Check for updates

Cite this: RSC Adv., 2019, 9, 5948

\title{
Effects of activated charcoal-herb extractum complex on the growth performance, immunological indices, intestinal morphology and microflora in weaning piglets $\dagger$
}

\author{
Liqi Wang, (D) a Limin Gong, ${ }^{a}$ Lin Zhu, ${ }^{a}$ Chucai Peng, ${ }^{a}$ Jianling Liao, ${ }^{b}$ Linfu Ke ${ }^{b}$ \\ and Bing Dong*a
}

This study was conducted to evaluate the effects of activated charcoal-herb extractum complex (CHC) on the growth performance, immunological indices, intestinal morphology and microflora in weaning piglets to determine the optimal supplemental dose. A total of 216 weaned piglets (Duroc $\times$ Landrace $\times$ Large White) with an initial body weight of $8.55 \pm 1.18 \mathrm{~kg}$ were randomly assigned to six treatment groups; each treatment group had six pens, with six pigs per pen. The study period was $28 \mathrm{~d}$. Pigs were fed a corn-soybean meal-based diet supplemented with 500,1000, 1500 or $2000 \mathrm{mg} \mathrm{kg}^{-1}$ of CHC over two 14-d periods. Two additional diets containing 0 and $1000 \mathrm{mg} \mathrm{kg}^{-1}$ of montmorillonite were set as the negative and positive controls, respectively. Supplementation with $500 \mathrm{mg} \mathrm{kg}^{-1}$ of $\mathrm{CHC}$ significantly increased average daily gain compared with the positive and negative controls during phase I and the entire experimental period $(P<0.05)$. During phase I, 500 and $1000 \mathrm{mg} \mathrm{kg}^{-1}$ of $\mathrm{CHC}$ significantly decreased diarrhea incidence compared with the negative control, and increased serum IGF-1 and serum IgM levels compared with the controls $(P<0.05)$. CHC at $500 \mathrm{mg} \mathrm{kg}^{-1}$ significantly decreased the diarrhea score during the entire experimental period compared with the negative control $(P<0.05)$. On day 28, supplementation with 500 and $1000 \mathrm{mg} \mathrm{kg}^{-1}$ of $\mathrm{CHC}$ increased serum IgG, IL-1 $\beta$, and duodenum and jejunum secretory IgA compared with the negative control and decreased duodenum and jejunum MDA levels compared with the controls $(P<0.05)$. Increased duodenum and jejunum villus height and an increased ratio of villus height to crypt depth were observed compared with the negative control and decreased viable counts of $E$. coli in the cecum were detected compared with the controls $(P<0.05)$. Collectively, the optimal dose of $\mathrm{CHC}$ was found to be 500 to $1000 \mathrm{mg} \mathrm{kg}^{-1}$ in this study.

Received 15th December 2018 Accepted 9th February 2019

DOI: 10.1039/c8ra10283j

rsc.li/rsc-advances pigs when the diet changes from the mother's milk to a solid plant-based diet. ${ }^{4}$

To tackle the problem of weaning gut infections and excess water loss from the gut tissue, both absorbents and antibiotics are employed. Absorbents, such as montmorillonite (MMT), can absorb toxins in feed and reduce toxin absorption by the intestines., ${ }^{5,6}$ Many studies have been conducted on the use of absorbents to reduce the toxin level in feedstuffs and diets, but a reliable solution has not been found. Antibiotics can help the body to reduce energy demand for the control of pathogen challenge, thus redirecting energy for growth, which has been the primary principle behind the use of antibiotics as growth promoters. ${ }^{7}$ Recently, serious concerns have been raised over the use of antibiotics in food-producing animal production. The European Union banned the application of antibiotics in livestock, and their use is only now allowed on veterinary prescription for direct applications or as a medicated feed since 2006. ${ }^{8}$ The Chinese Ministry of Agriculture (MOA) has also gradually reduced the types and doses of antibiotics allowed in
${ }^{a}$ State Key Laboratory of Animal Nutrition, China Agricultural University, No. 2 Yuanmingyuan West Road, Haidian District, Beijing 100193, P. R. China. E-mail: dongbing@cau.edu.cn; Fax: +86-10-62733688; Tel: +86-10-62733588 ${ }^{b}$ Fujian Baicaoshaung Biotechnology Co., Ltd., Nanping 353200, P. R. China $\dagger$ Electronic supplementary information (ESI) available. See DOI: 10.1039/c8ra10283j 
feed since 2017, with the intention of banning the use of antibiotics as feed additives by 2020. In developing countries, removing the prophylactic use of antibiotics from livestock feed poses considerable challenges including pathogen-induced post-weaning diarrhea because of the limitations on environmental control for livestock husbandry. ${ }^{9}$ Researchers are seeking alternatives to antibiotics that are effective and do not have an environmental impact. ${ }^{10}$

Charcoal is a crystalline form of carbon produced by carbonaceous plants in the form of cellulose, wood and industrial byproducts $^{\mathbf{1 1}}$ following treatment at high temperature in the absence of oxygen. Activated charcoal, produced in the presence of an activation reagent, is highly porous and thus can trap chemicals efficiently. This fine, odorless, tasteless, black powder works as a physical absorbent for toxins and gases by using its porous structure and alkali bonds generated during activation. ${ }^{12}$ Activated charcoal has been demonstrated to be an effective additive to promote intestinal structure and morphology in chickens ${ }^{13}$ and piglets, a balanced intestinal microflora in piglets, ${ }^{14}$ and enhanced feed intake in goats. ${ }^{15}$ Activated charcoal is also used as a gas absorbent for nitrogen and ammonia to control the atmosphere in livestock housing facilities.

Many Chinese herbs, recorded in ancient Chinese medical books, are used as natural plant remedies. Pulsatilla chinensis is recorded as an anti-bacterial herb functioning within the stomach and large intestine for detoxification. ${ }^{\mathbf{1 6}}$ In recent research, the immunopotentiating, anti-oxidant and antitumor activities of $P$. chinensis were reported. ${ }^{17}$ Portulaca oleracea $\mathrm{L}$. is a widespread medicinal plant that is used not only as an edible plant but also as a traditional medicine for alleviating a wide spectrum of diseases including gastrointestinal diseases and severe inflammation. ${ }^{18}$ It has also been linked with strong antioxidant activity and a reduction in the blood fat content. ${ }^{19}$ Two additional herbs, Artemisia argyi Folium and Pteris multifida Poir, are also considered to have anti-bacterial properties and are widely used in herbal medicine in China and several other countries. ${ }^{20}$

In this study, a complex of activated charcoal and herb extractum (CHC) was prepared. Its effects on growth performance, diarrhea score and diarrhea incidence, immune responses, intestinal morphology, and intestinal microflora were evaluated in weaning pigs. This complex combines the functions of multiple additives into a single product to tackle several problems encountered in weaning piglets.

\section{Experimental}

\section{Materials and methods}

Preparation of CHC. CHC was obtained from the Fujian Baicaoshaung Biotechnology Co., Ltd (Nanping, China), and prepared from cedarwood and pine wood and a selection of Chinese herbs. The raw materials were produced using three main processes. Firstly, the material (cedarwood and pine wood) was crushed and sieved to reduce particle size, then carbonized and activated at high temperature. Only fractions in the size range of 0.18 to $0.25 \mathrm{~mm}$ were subjected to the final step. Traditional Chinese herbs including Pulsatilla chinensis, Portulaca oleracea L., Artemisia argyi Folium and Pteris multifida Poir were prepared by washing, soaking, water boiling and extraction. After decompressing and concentrating, the extractum mixed with starch was ground and sieved to particle sizes of 0.18 to $0.25 \mathrm{~mm}$. Finally, activated materials were mixed with Chinese herbal extractum in appropriate proportions to create the final CHC product.

Characterization of CHC and MMT. MMT was obtained from Qingdao Continent Animal Pharmaceutical Co., Ltd. (Shandong, China). High-resolution scanning electron microscopy (SEM) was used to study the pore development of MMT and CHC. The specific surface area and aperture were tested using a V-Sorb 2800P specific surface area and aperture distribution tester (Beijing Gold Spectrum Technology Co., Ltd., Beijing, China). The carbon, hydrogen and nitrogen contents of CHC were determined using Vario EL III CHNS Analyzer (Elementar Analysensysteme GmbH, Langenselbold, Germany).

Animals, diets and experimental design. A total of 216 pigs (Duroc $\times$ Landrace $\times$ Large White) weaned at 28 days of age were raised at the Swine Nutrition Research Center of the National Feed Engineering Technology Research Center (Chengde, Hebei Province, China). Pigs with an initial body weight of $8.55 \pm 1.18 \mathrm{~kg}$ were randomly assigned to six treatment groups: a corn-soybean meal basal diet supplemented with $500,1000,1500$ or $2000 \mathrm{mg} \mathrm{kg}^{-1}$ of CHC, or 0 or $1000 \mathrm{mg}$ $\mathrm{kg}^{-1}$ of MMT supplement as the negative and positive controls, respectively. The basal diet was formulated to meet or exceed National Research Council (2012) estimates of the nutrient requirements of weaned pigs (Table 1). Each treatment was performed on six pens containing six pigs including three barrows and three gilts per pen. Each pen was equipped with a stainless-steel feeder and a nipple drinker. All pigs were given ad libitum access to feed and water for 28 days comprising two phases (d 0-14 and d 15-28).

All animal procedures and animal care were approved by the Institution Animal Care and Use Committee at China Agricultural University (201605510410554).

Sample collection. Each piglet was weighed on d 0, 14 and 28 , and feed consumption was also recorded on a pen basis to determine average daily gain (ADG), average daily feed intake (ADFI) and the feed to gain ratio $(F: R)$. Thirty-six pigs $(1$ pig from each pen) were selected randomly to collect blood on $\mathrm{d} 0$, 14 and 28. Serum samples were separated by centrifugation at $3000 \times g$ at $4{ }^{\circ} \mathrm{C}$ for $10 \mathrm{~min}$ and stored at $-20{ }^{\circ} \mathrm{C}$ until needed for analysis. The pigs from which blood had been sampled were euthanized by electrical stunning followed by exsanguination following a $12 \mathrm{~h}$ fasting on $\mathrm{d} 28$. The small intestine was dissected from the mesentery and immediately placed on ice. The duodenum was considered as the part of the intestine from the pylorus to the ligament of Treitz, a segment of the small intestine $10 \mathrm{~cm}$ proximal to the ileocecal junction was considered as the ileum, and the remainder of the small intestine was considered as the jejunum. After slitting lengthwise and gentle rinsing with ice-cold PBS, the mucosa from the mid-duodenum, mid-jejunum and mid-ileum were scraped with a glass slide and then rapidly placed in liquid nitrogen for the measurement of 
Table 1 The composition and analyzed nutrient levels of basal diets $(\% \text {, as-fed basis })^{a}$

\begin{tabular}{lrr}
\hline Items & Phase I & Phase II \\
\hline Corn & 59.15 & 60.49 \\
Soybean meal (45\% crude protein) & 14.31 & 18.08 \\
Soybean oil & 2.80 & 2.60 \\
Fish meal & 2.40 & 2.20 \\
Soy protein concentrate & 10.10 & 4.80 \\
Whey powder (12\% crude protein) & 7.32 & 8.29 \\
Dicalcium phosphate & 1.26 & 1.10 \\
Limestone & 0.72 & 0.60 \\
Salt & 0.24 & 0.24 \\
L-Lysine-HCl & 0.51 & 0.50 \\
L-Threonine & 0.18 & 0.15 \\
Tryptophan & 0.03 & 0.03 \\
Methionine hydroxy analogue & 0.28 & 0.23 \\
Choline chloride $(50 \%)$ & 0.20 & 0.20 \\
Vitamine-mineral premix & $b$ & 0.50 \\
Total & 100.00 & 100.00
\end{tabular}

\section{Analyzed nutrient levels ${ }^{c}$}

Digestible energy, Mcal kg ${ }^{-1}$

Dry matter

Crude protein

Ash

Ether extract

Crude fiber

Lysine

Methionine

Methionine + cystine

Threonine

Calcium

Total phosphorus

${ }_{b}^{a}$ Corn was replaced with MMT or CHC in the other treatments.

$b$ Provided per kg of diet: vitamin A, $12000 \mathrm{IU}$; vitamin D3, $2000 \mathrm{IU}$; vitamin E, $30 \mathrm{IU}$; vitamin $\mathrm{K} 3,2.5 \mathrm{mg}$; thiamine, $2.5 \mathrm{mg}$; riboflavin, $4 \mathrm{mg}$; pyridoxine, $3 \mathrm{mg}$; vitamin $\mathrm{B} 12,20 \mu \mathrm{g}$; niacin, $40 \mathrm{mg}$; pantothenic acid, $12.5 \mathrm{mg}$; folic acid, $0.7 \mathrm{mg}$; biotin, $0.07 \mathrm{mg}$; Fe, $100 \mathrm{mg}$; Cu, $90 \mathrm{mg}$; Zn, $80 \mathrm{mg}$; Mn, $30 \mathrm{mg}$; I, $0.25 \mathrm{mg}$; Se, $0.15 \mathrm{mg}$. ${ }^{c}$ All data are analyzed values except for digestible energy.

intestinal immunological indices. Meanwhile, segments $(2 \mathrm{~cm}$ in length) of the middle parts of the duodenum, jejunum and ileum (the entire alimentary canal without any digesta) were fixed in $10 \%$ neutral buffered formalin for subsequent morphological examination. The gut contents from the ileum, cecum and colon were collected into sterile plastic bags and immediately chilled on dry ice for the analysis of microbial populations.

Chemical analysis of feed. Basel diets were analyzed according to AOAC (2012) procedures including crude protein, lysine, methionine, calcium and total phosphorus. Amino acid analyses were performed using high-performance liquid chromatography (Hitachi L-8800 Amino Acid Analyzer, Tokyo, Japan).

Diarrhea score and diarrhea incidence. The pigs were observed for clinical signs of diarrhea throughout the experiment by two independent assessors and diarrhea scores were assigned according to the previously described system from 0 to 3. A score of 0 represented feces that was firm and normally shaped, scores of 1, 2 and 3 represented feces that was soft (retained some shape), brown liquid, or frequent passage of watery feces, respectively. Scores were recorded on a pen basis following observations of an individual pig. Diarrhea incidence was calculated using the following formula.

Diarrhea incidence $=\Sigma($ diarrhea days $) /($ pig days $) \times 100 \%$

Diarrhea days $=$ number of pigs $\times$ the number of days of diarrhea score

Pig days $=$ number of pigs $\times$ the number of experiment days

Immunological indices. Serum immunoglobulins $\mathrm{A}, \mathrm{M}$ and G (IgA, IgM and IgG) were measured on an automatic biochemical analyzer (Hitachi 7600, Hitachi High-Technologies Corporation, Tokyo, Japan), following the instructions that accompanied commercially available kits (Nanjing Jiancheng Bioengineering Institute, Nanjing, China). Serum interleukin$1 \beta$ (IL-1 $\beta$ ) and interferon- $\gamma$ (INF- $\gamma$ ) were assayed following the instructions that accompanied commercially available kits (eBioscience, San Diego, CA, USA) using a microplate reader (Multiskan MK3 microplate reader, Waltham, MA, USA). Intestinal secretory immunoglobulin A (SIgA) levels were assayed using an Sn-69513-type immune counter (Shanghai Nucleus Annular Photoelectric Instrument Co., Ltd., Shanghai, China). Malondialdehyde (MDA) levels were determined with 2-thiobarbituric acid at $532 \mathrm{~nm}$.

Morphology analysis. Intestinal tissues including the middle parts of the duodenum, jejunum and ileum were fixed in $10 \%$ formalin and dehydrated in ethanol, cleared with xylene, and embedded in paraffin according to regular morphology processing. Sections ( $6 \mu \mathrm{m}$ thick) were stained with hematoxylin and eosin for identification. Six representative villi (determined as the distance between the crypt opening and the end of the villus) and their associated crypts (measured from the cryptvillus junction to the base of the crypt) were selected per section and measured under a light microscope (Nikon, Tokyo, Japan) at a $40 \times$ magnification and were analyzed using Image-pro plus 6.0 software. Villus height, crypt depth and the ratio of villus height to crypt depth were calculated and the average of these measurements was determined to yield a single value for each pig.

Microbial analysis. For microbial analysis, approximately $1 \mathrm{~g}$ of the gut contents from the ileum, cecum and colon were mixed with $9 \mathrm{~mL}$ of reduced sterile diluted blank solution and homogenized, then subsequently diluted to $10^{-2}, 10^{-3}, 10^{-4}$ and $10^{-5}$ for the analysis of Escherichia coli (MacConkey agar, Beijing Haidian Microbiological Culture Factory, Beijing, China), Lactobacilli (MRS agar, De Man, Rogosa, Sharpe Media; Oxoid Ltd., Basingstoke, UK; CM0361, anaerobic chamber), total microbes including total anaerobes (plate-count agar, anaerobic chamber) and total aerobes (plate-count agar). All of the inoculated plates were incubated at $37^{\circ} \mathrm{C}$. Total numbers of bacterial colonies were counted at the end of each incubation period. Only plates (or replicate plates from the same dilution) 
with 30-300 colonies were counted. Usually, more than one dilution in a series was plated to ensure that results in a countable range were obtained. Dilutions giving results outside of the countable range were not included in the final analysis. The microbial enumerations were expressed as the $\mathrm{lg}$ (CFU g $\left.{ }^{-1}\right)$.

Statistical analysis. Data were analyzed as a completely randomized design by weight using one-way analysis of variance (ANOVA) according to the GLM procedures of SAS 9.2 (SAS Institute Inc., Cary, NC, USA), which included terms for treatment. A pen served as the experimental unit for growth performance and an individual pig was the experimental unit for the other indices. Differences among means were tested using Duncan's multiple range test. Coefficients for unequally spaced contrasts were generated by the interactive matrix algebra procedure (IML) of SAS, after which the linear and quadratic responses of $\mathrm{CHC}$ were assessed using orthogonal polynomial contrast. Significance was declared at $P<0.05$.

\section{Results}

\section{Physical characteristics of CHC compared with MMT}

As shown in Fig. 1A, SEM revealed that $\mathrm{CHC}$ had a more developed aperture structure than MMT. Regarding surface area and iodine sorption value, CHC was superior to MMT (Fig. 1B). As for elemental composition, approximately $90 \%$ of $\mathrm{CHC}$ is carbon (ESI Fig. $1 \dagger$ ). A comparison between surface area, pore volume and pore size between MMT and CHC is shown in ESI Table $1 \dagger$ and revealed that $\mathrm{CHC}$ has a higher specific surface area and more well-developed pore distribution than MMT. In the experiments in vitro, CHC was able to adsorb mycotoxins including deoxynivalenol (DON), zearalenone (ZEN), fumonisins B1 (AFB1) and ochratoxin A (OTA) under different processing conditions, and formed a stable complex (unpublished data).

\section{Growth performance and postweaning diarrhea}

Table 2 shows the effects of graded levels of CHC on growth performance in weaned piglets. Compared with the two control groups, the pigs fed $500 \mathrm{mg} \mathrm{kg}{ }^{-1}$ CHC showed a significantly greater ADG during phase I (d 0-14) and over the whole experimental period (d $0-28$ ). Whereas the ADFI and $F: G$ ratio were not affected by treatment over the time period. As for the diarrhea score and incidence of diarrhea, pigs fed $500 \mathrm{mg} \mathrm{kg}^{-1}$ of CHC had a lower diarrhea score than other treatments over the experimental period (d 0-28). Similarly, during phase I, supplementation with 500 and $1000 \mathrm{mg} \mathrm{kg}^{-1}$ of CHC significantly decreased the incidence of diarrhea.

\section{Serum immunological parameters}

Table 3 lists the effects of graded levels of CHC on serum immunological parameters in weaned piglets. The results showed no differences among any of the groups on $\mathrm{d} 0$, which indicated that the pigs were in similar physical condition to the start of the experiment. On d 14, serum IgM was significantly higher in the pigs fed 500 and $1000 \mathrm{mg} \mathrm{kg}^{-1}$ of CHC than in the controls $(P<0.01)$. Similarly, supplementation with 500 and $1000 \mathrm{mg} \mathrm{kg}{ }^{-1}$ CHC significantly increased serum IgG $(P<0.05)$ and IL-1 $\beta(P<0.05)$ compared with the negative control on $\mathrm{d} 28$.

\section{Intestinal immunological parameters}

As shown in Fig. 2, pigs fed 500 and $1000 \mathrm{mg} \mathrm{kg}^{-1}$ of CHC had higher levels of SIgA in their duodenum and jejunum compared with the positive and negative controls $(P<0.05)$. A decreased
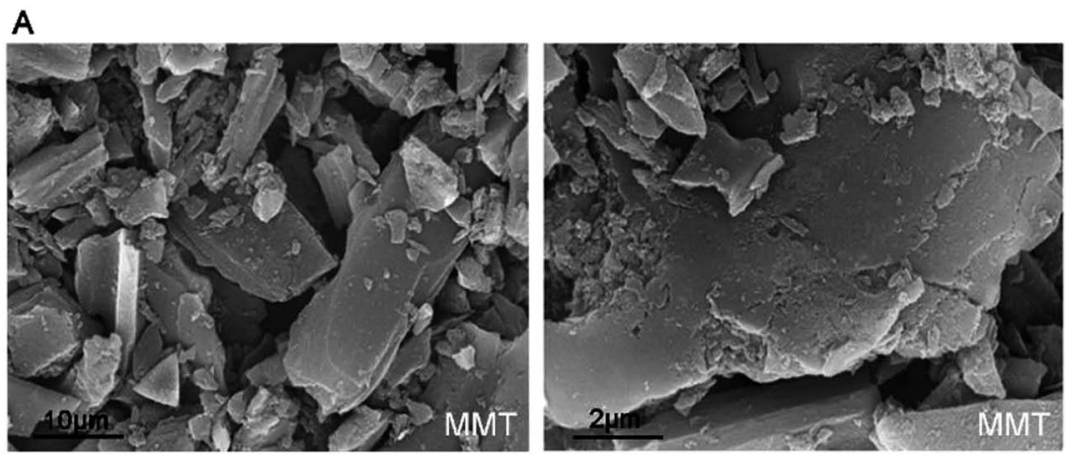

B
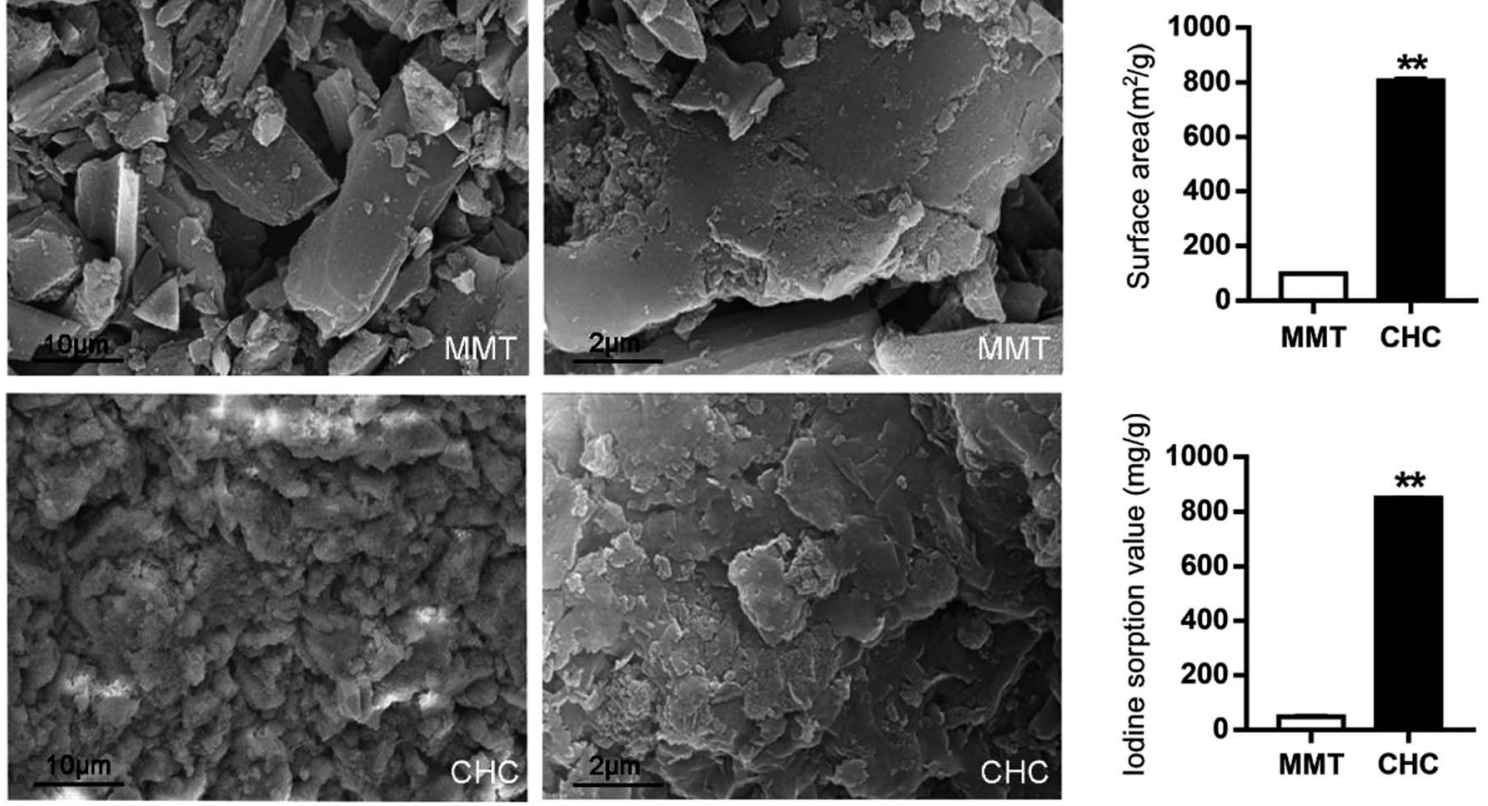

Fig. 1 The physical characteristics of MMT and CHC. (A) The pore development of MMT and CHC as analyzed by high-resolution scanning electron microscopy (SEM). (B) The physical characteristics, including surface area and iodine sorption value, of MMT and CHC. 
Table 2 Effects of graded levels of $\mathrm{CHC}$ on growth performance in weaned piglets ${ }^{a}(n=6)$

\begin{tabular}{|c|c|c|c|c|c|c|c|c|c|c|}
\hline \multirow[b]{2}{*}{ Items } & \multirow{2}{*}{$\begin{array}{l}\text { MMT, mg } \\
\mathrm{kg}^{-1}, 1000\end{array}$} & \multicolumn{5}{|c|}{$\mathrm{CHC}, \mathrm{mg} \mathrm{kg}^{-1}$} & \multirow[b]{2}{*}{ SEM } & \multicolumn{3}{|l|}{$P$ value } \\
\hline & & 0 & 500 & 1000 & 1500 & 2000 & & ANOVA & Linear & Quadratic \\
\hline \multicolumn{11}{|l|}{$\mathbf{B W}^{b}$} \\
\hline $0 \mathrm{~d}, \mathrm{~kg}$ & 8.55 & 8.55 & 8.54 & 8.54 & 8.55 & 8.55 & 0.02 & 0.99 & 0.73 & 0.86 \\
\hline $14 \mathrm{~d}, \mathrm{~kg}$ & $13.17^{\mathrm{b}}$ & $13.13^{\mathrm{b}}$ & $13.78^{\mathrm{a}}$ & $13.41^{\mathrm{ab}}$ & $13.07^{\mathrm{b}}$ & $13.02^{\mathrm{b}}$ & 0.17 & 0.04 & 0.10 & 0.06 \\
\hline $28 \mathrm{~d}, \mathrm{~kg}$ & $20.56^{\mathrm{b}}$ & $20.78^{\mathrm{b}}$ & $22.10^{\mathrm{a}}$ & $21.45^{\mathrm{ab}}$ & $20.89^{\mathrm{b}}$ & $20.85^{\mathrm{b}}$ & 0.35 & 0.05 & 0.04 & 0.15 \\
\hline \multicolumn{11}{|l|}{ 0-14 d } \\
\hline $\mathrm{ADG}, \mathrm{kg}$ & $0.33^{\mathrm{b}}$ & $0.33^{\mathrm{b}}$ & $0.37^{\mathrm{a}}$ & $0.35^{\mathrm{ab}}$ & $0.32^{\mathrm{b}}$ & $0.32^{\mathrm{b}}$ & 0.01 & 0.04 & 0.11 & 0.07 \\
\hline ADFI, $\mathrm{kg}$ & 0.50 & 0.52 & 0.55 & 0.52 & 0.51 & 0.51 & 0.01 & 0.16 & 0.27 & 0.10 \\
\hline$F: G$ & 1.54 & 1.60 & 1.49 & 1.51 & 1.60 & 1.60 & 0.03 & 0.12 & 0.15 & 0.28 \\
\hline Diarrhea score & 1.28 & 1.44 & 0.90 & 1.11 & 1.69 & 1.69 & 0.26 & 0.21 & 0.52 & 0.14 \\
\hline Diarrhea incidence\% & $5.28^{\mathrm{ab}}$ & $7.14^{\mathrm{a}}$ & $3.17^{\mathrm{b}}$ & $3.77^{\mathrm{b}}$ & $5.60^{\mathrm{ab}}$ & $5.95^{\mathrm{ab}}$ & 0.89 & 0.04 & 0.05 & 0.93 \\
\hline \multicolumn{11}{|l|}{$15-28 d$} \\
\hline $\mathrm{ADG}, \mathrm{kg}$ & 0.53 & 0.55 & 0.59 & 0.57 & 0.56 & 0.56 & 0.02 & 0.14 & 0.10 & 0.56 \\
\hline ADFI, kg & 0.83 & 0.86 & 0.89 & 0.88 & 0.86 & 0.89 & 0.03 & 0.76 & 0.62 & 0.94 \\
\hline$F: G$ & 1.58 & 1.59 & 1.48 & 1.53 & 1.53 & 1.60 & 0.04 & 0.45 & 0.34 & 0.70 \\
\hline Diarrhea score & 0.89 & 1.17 & 0.44 & 0.61 & 1.14 & 1.08 & 0.21 & 0.10 & 0.18 & 0.37 \\
\hline Diarrhea incidence\% & 4.88 & 4.17 & 3.17 & 5.16 & 4.56 & 3.77 & 0.90 & 0.65 & 0.20 & 0.28 \\
\hline \multicolumn{11}{|l|}{$0-28 d$} \\
\hline $\mathrm{ADG}, \mathrm{kg}$ & $0.43^{\mathrm{b}}$ & $0.44^{\mathrm{b}}$ & $0.48^{\mathrm{a}}$ & $0.46^{\mathrm{ab}}$ & $0.44^{\mathrm{b}}$ & $0.44^{\mathrm{b}}$ & 0.01 & $<0.05$ & 0.04 & 0.13 \\
\hline ADFI, kg & 0.67 & 0.69 & 0.72 & 0.70 & 0.69 & 0.70 & 0.02 & 0.56 & 0.39 & 0.43 \\
\hline$F: G$ & 1.57 & 1.59 & 1.48 & 1.52 & 1.55 & 1.59 & 0.03 & 0.16 & 0.14 & 0.49 \\
\hline Diarrhea score & $1.08^{\mathrm{abc}}$ & $1.31^{\mathrm{ab}}$ & $0.65^{\mathrm{c}}$ & $0.86^{\mathrm{bc}}$ & $1.42^{\mathrm{a}}$ & $1.39^{\mathrm{a}}$ & 0.16 & 0.01 & 0.18 & 0.09 \\
\hline Diarrhea incidence\% & 5.08 & 5.66 & 3.18 & 4.47 & 5.08 & 4.86 & 0.58 & 0.10 & 0.03 & 0.44 \\
\hline
\end{tabular}

${ }^{a} \mathrm{a}, \mathrm{b}, \mathrm{c}$ Means within the same row without common superscripts differ significantly $(P<0.05) .{ }^{b}$ SEM standard error of the means, BW body weight, ADG average daily gain, ADFI average daily feed intake, $F: G$ feed to gain ratio.

concentration of MDA in the duodenum and jejunum was observed in pigs fed 500 and $1000 \mathrm{mg} \mathrm{kg}^{-1}$ of CHC $(P<0.05)$. There was no effect of treatment observed in the ileum.

\section{Intestinal morphology}

Dietary supplementation with 500 or $1000 \mathrm{mg} \mathrm{kg}^{-1}$ of $\mathrm{CHC}$ increased the duodenum villus height and the ratio of villus

Table 3 Effects of graded levels of $\mathrm{CHC}$ on serum immunological parameters in weaned piglets ${ }^{a}(n=6)$

\begin{tabular}{|c|c|c|c|c|c|c|c|c|c|c|}
\hline \multirow[b]{2}{*}{ Items } & \multirow{2}{*}{$\begin{array}{l}\text { MMT, mg } \\
\mathrm{kg}^{-1}, 1000\end{array}$} & \multicolumn{5}{|c|}{$\mathrm{CHC}, \mathrm{mg} \mathrm{kg}{ }^{-1}$} & \multirow[b]{2}{*}{ SEM } & \multicolumn{3}{|l|}{$P$ value } \\
\hline & & 0 & 500 & 1000 & 1500 & 2000 & & ANOVA & Linear & Quadratic \\
\hline \multicolumn{11}{|l|}{$\mathbf{0} \mathbf{d}^{b}$} \\
\hline $\operatorname{IgM}, g^{-1}$ & 0.70 & 0.76 & 0.94 & 0.84 & 0.71 & 0.88 & 0.07 & 0.25 & 0.14 & 0.37 \\
\hline IgA, $\mathrm{g} \mathrm{L}^{-1}$ & 1.08 & 1.06 & 0.94 & 0.91 & 1.04 & 0.83 & 0.13 & 0.75 & 0.54 & 0.89 \\
\hline $\operatorname{IgG}, \mathrm{g} \mathrm{L}^{-1}$ & 9.84 & 8.34 & 9.53 & 10.13 & 9.18 & 9.06 & 0.36 & 0.09 & 0.28 & 0.30 \\
\hline $\mathrm{IL}-1 \beta, \mathrm{pg} \mathrm{mL}^{-1}$ & 51.77 & 55.50 & 57.93 & 54.30 & 54.51 & 54.94 & 1.17 & 0.13 & 0.49 & 0.09 \\
\hline IFN- $\gamma$, pg mL ${ }^{-1}$ & 68.49 & 71.05 & 76.53 & 70.80 & 75.17 & 75.83 & 2.80 & 0.26 & 0.06 & 0.85 \\
\hline \multicolumn{11}{|l|}{$14 \mathrm{~d}$} \\
\hline IgM, g L $L^{-1}$ & $0.85^{\mathrm{c}}$ & $0.77^{\mathrm{c}}$ & $1.54^{\mathrm{ab}}$ & $1.76^{\mathrm{a}}$ & $1.13^{\mathrm{bc}}$ & $1.15^{\mathrm{bc}}$ & 0.16 & $<0.01$ & 0.09 & 0.67 \\
\hline IgA, $g^{-1}$ & 1.42 & 1.14 & 1.05 & 1.17 & 1.37 & 1.07 & 0.14 & 0.34 & 0.48 & 0.21 \\
\hline IgG, $\mathrm{g} \mathrm{L}^{-1}$ & 8.63 & 9.60 & 10.23 & 11.10 & 9.26 & 9.45 & 0.73 & 0.26 & 0.88 & 0.85 \\
\hline $\mathrm{IL}-1 \beta, \mathrm{pg} \mathrm{mL}^{-1}$ & 48.14 & 53.45 & 49.15 & 57.57 & 58.71 & 61.32 & 5.10 & 0.38 & 0.77 & 0.13 \\
\hline IFN- $\gamma, p g \mathrm{~mL}^{-1}$ & 58.61 & 66.17 & 63.42 & 60.12 & 59.24 & 61.97 & 2.90 & 0.45 & 0.71 & 0.12 \\
\hline \multicolumn{11}{|l|}{$28 \mathrm{~d}$} \\
\hline $\operatorname{IgM}, \mathrm{g} \mathrm{L}^{-1}$ & 0.78 & 1.04 & 1.39 & 1.44 & 0.94 & 1.06 & 0.19 & 0.15 & 0.66 & 0.56 \\
\hline IgA, $g^{-1}$ & 1.29 & 1.27 & 1.12 & 1.19 & 1.46 & 1.05 & 0.12 & 0.23 & 0.18 & 0.34 \\
\hline IgG, $g^{-1}$ & $10.54^{\mathrm{a}}$ & $8.66^{\mathrm{b}}$ & $10.85^{\mathrm{a}}$ & $10.70^{\mathrm{a}}$ & $9.67^{\mathrm{ab}}$ & $9.96^{\mathrm{ab}}$ & 0.48 & 0.03 & 0.02 & 0.58 \\
\hline $\mathrm{IL}-1 \beta, \mathrm{pg} \mathrm{mL}^{-1}$ & $75.60^{\mathrm{ab}}$ & $65.81^{\mathrm{b}}$ & $92.96^{\mathrm{a}}$ & $91.37^{\mathrm{a}}$ & $66.81^{\mathrm{b}}$ & $60.27^{\mathrm{b}}$ & 7.31 & 0.01 & 0.37 & 0.28 \\
\hline IFN- $\gamma$, pg mL & 62.28 & 62.62 & 62.54 & 61.05 & 59.56 & 59.69 & 2.34 & 0.87 & 0.82 & 0.19 \\
\hline
\end{tabular}

${ }^{a}$ a,b,c Means within the same row without common superscripts differ significantly $(P<0.05) .{ }^{b}$ IgM immune globulin M, IgA immune globulin A, IgG immune globulin G, IL-1 $\beta$ interleukin- $1 \beta$, IFN- $\gamma$ interferon- $\gamma$. 

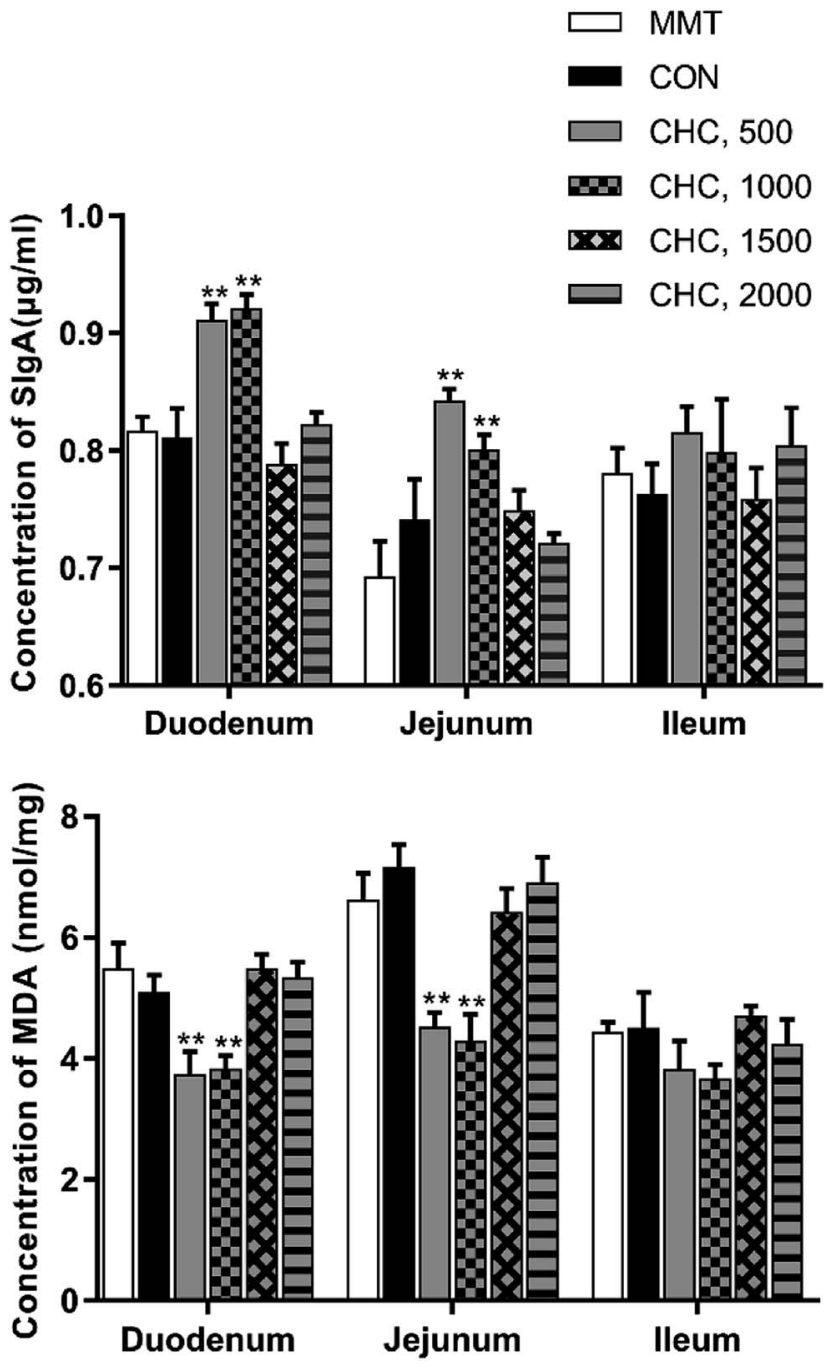

Fig. 2 Effects of graded levels of $\mathrm{CHC}$ on the intestinal mucosa SIgA and MDA levels in weaned piglets $(n=6)$. *Represents a significant difference between groups $(P<0.05)$, **represents a significant difference between groups $(P<0.01)$. CHC, 500, 1000, 1500 and 2000 indicate the amount of $\mathrm{CHC}$ added as a dietary supplement, i.e., 500, 1000,1500 and $2000 \mathrm{mg} \mathrm{kg}^{-1}$ of $\mathrm{CHC}$ per group, respectively.

height to crypt depth, compared with the controls $(P<0.05)$. Pigs fed diets supplemented with 500, 1000 or $1500 \mathrm{mg} \mathrm{kg} \mathrm{kg}^{-1}$ CHC had a greater villus height in the jejunum than the negative control $(P<0.05)$. The villus height to crypt depth ratio of the jejunum was significantly greater in the 500 and $1000 \mathrm{mg}$ $\mathrm{kg}^{-1}$ groups and the positive control compared with the negative control $(P<0.01)$. The villus height, crypt depth and the villus height to crypt depth ratio in the ileum did not differ among all of the treatment groups (Table 4).

\section{Intestinal microflora}

The effect of graded levels of $\mathrm{CHC}$ on the intestinal microflora in weaning piglets is shown in Table 5 . Viable counts of $E$. coli in the cecum were significantly lower after supplementation with 500 or $1000 \mathrm{mg} \mathrm{kg}^{-1} \mathrm{CHC}$ compared with the controls and there was no effect in the ileum or colon $(P<0.01)$.

\section{Serum hormones}

The effect of graded levels of $\mathrm{CHC}$ on the serum hormones is presented in Table 6. The concentration of Insulin-like growth factor 1 (IGF-1) was significantly greater $(P<0.01)$ on $d 14$ than for all other treatment groups when diets contained 500 or $1000 \mathrm{mg} \mathrm{kg}^{-1}$ CHC. Pigs fed a negative control diet had the lowest levels of IGF-1, with no difference between pigs fed MMT and those fed 1500 or $2000 \mathrm{mg} \mathrm{kg}^{-1} \mathrm{CHC}$. The levels of growth hormone (GH), insulin (INS), IGF-1 and cortisol (COR) were not affected by treatment on $\mathrm{d} 28$. There was no linear or quadratic response observed for serum hormone levels on d 14 or 28.

\section{Discussion}

Weaning imposes considerable stress on pigs and is accompanied by the need to adapt to nutritional, immunological and psychological disruptions. Digestive disorders, postweaning diarrhea and impaired performance are common problems among weaning piglets. ${ }^{21}$ Previously, antibiotics were widely used in animal feed as growth promoters, to decrease the animal's susceptibility to infectious agents, and improve production. However, it is now thought that the continuous usage of antibiotics may contribute to the emergence of a reservoir of drug-resistant bacteria, which may then transfer their resistance to pathogenic bacteria in both animals and humans. As a result, much research has been focused on alternative feeding strategies that can maintain pig performance and health. ${ }^{7}$

Adsorbents like clay and activated charcoal are potentially good alternatives to antibiotics. Absorbents prevent diarrhea by absorbing toxins and hence, reducing toxin absorption by the intestinal tract. Absorbents are characterized by a porous structure and enlarged surface area. MMT is formed by a $2: 1$ condensation of layers structured as aluminum sandwiched between layers of silica. It can absorb organic materials either on its surface or within its internal spaces via cation exchange between layers. ${ }^{22} \mathrm{MMT}$ is one type of representative clay adsorbent for treating pig enteric diseases. However, while some studies report MMT to be effective in promoting growth performance, intestinal morphology, ${ }^{23}$ beneficial bacteria, ${ }^{24}$ reducing the diarrhea rate and inhibiting harmful bacterial strains, other studies report no improvements in pig performance as a result of feeding with MMT. ${ }^{23,25}$

Many plants can be prepared as activated charcoal. Activated charcoal can be applied in the treatment of diarrhea as an absorbent to attract materials allowing their clearance from the body in human symptomatic therapy. ${ }^{26}$ In animal models, activated charcoal can slow gastrointestinal transit and help to eliminate excess moisture. Additionally, activated charcoal is deemed as an anti-bacterial and anti-viral material. Several studies on bamboo charcoal have been performed in aquatic animals, ${ }^{27}$ ducks and fattening pigs. ${ }^{28}$ To our knowledge, there are few studies reported on the effects of activated carbon in weaning piglets.

In this study, we used the soot derived from cedar wood and pine wood to develop an activated charcoal product. To enhance 
Table 4 Effects of graded levels of $\mathrm{CHC}$ on intestinal morphology in weaned piglets ${ }^{a}(n=6)$

\begin{tabular}{|c|c|c|c|c|c|c|c|c|c|c|}
\hline \multirow[b]{2}{*}{ Items } & \multirow{2}{*}{$\begin{array}{l}\text { MMT, mg } \\
\mathrm{kg}^{-1} \\
1000\end{array}$} & \multicolumn{5}{|c|}{$\mathrm{CHC}, \mathrm{mg} \mathrm{kg}{ }^{-1}$} & \multirow[b]{2}{*}{ SEM } & \multicolumn{3}{|l|}{$P$ value } \\
\hline & & 0 & 500 & 1000 & 1500 & 2000 & & ANOVA & Linear & Quadratic \\
\hline \multicolumn{11}{|l|}{ Duodenum } \\
\hline Villous height, $\mu \mathrm{m}$ & $347.20^{\mathrm{b}}$ & $338.40^{\mathrm{b}}$ & $422.60^{\mathrm{a}}$ & $432.40^{\mathrm{a}}$ & $335.40^{\mathrm{b}}$ & $300.85^{\mathrm{b}}$ & 22.29 & $<0.01$ & 0.41 & 0.32 \\
\hline Crypt depth, $\mu \mathrm{m}$ & 272.20 & 277.80 & 284.60 & 283.60 & 254.00 & 261.60 & 19.84 & 0.85 & 0.90 & 0.39 \\
\hline$V: C$ ratio & $1.28^{\mathrm{bc}}$ & $1.22^{\mathrm{c}}$ & $1.49^{\mathrm{a}}$ & $1.52^{\mathrm{a}}$ & $1.34^{\mathrm{abc}}$ & $1.31^{\mathrm{abc}}$ & 0.07 & 0.03 & 0.16 & 0.78 \\
\hline \multicolumn{11}{|l|}{ Jejunum } \\
\hline Villous height, $\mu \mathrm{m}$ & $345.40^{\mathrm{ab}}$ & $272.40^{\mathrm{b}}$ & $366.20^{\mathrm{a}}$ & $398.75^{\mathrm{a}}$ & $350.00^{\mathrm{a}}$ & $344.40^{\mathrm{ab}}$ & 23.76 & 0.04 & 0.08 & 0.06 \\
\hline Crypt depth, $\mu \mathrm{m}$ & 247.60 & 259.40 & 269.20 & 267.50 & 295.60 & 286.20 & 17.14 & 0.42 & 0.49 & 0.15 \\
\hline$V: C$ ratio & $1.40^{\mathrm{ab}}$ & $1.05^{\mathrm{c}}$ & $1.37^{\mathrm{ab}}$ & $1.53^{\mathrm{a}}$ & $1.19^{\mathrm{bc}}$ & $1.16^{\mathrm{bc}}$ & 0.07 & $<0.01$ & 0.28 & 0.43 \\
\hline \multicolumn{11}{|l|}{ Ileum } \\
\hline Villous height, $\mu \mathrm{m}$ & 339.50 & 328.80 & 362.40 & 344.00 & 266.00 & 305.00 & 26.62 & 0.11 & 0.72 & 0.06 \\
\hline Crypt depth, $\mu \mathrm{m}$ & 244.50 & 248.60 & 255.00 & 258.20 & 210.40 & 231.40 & 183.98 & 0.11 & 0.73 & 0.06 \\
\hline$V: C$ ratio & 1.40 & 1.33 & 1.44 & 1.35 & 1.28 & 1.35 & 0.13 & 0.96 & 0.59 & 0.59 \\
\hline
\end{tabular}

its anti-microbial activity, a batch of extractum of Chinese herbs (Pulsatilla chinensis, Portulaca oleracea L., Artemisiae argyi Folium and Pteris multifida Poir) was mixed with the soot. The effects of this complex of active charcoal and extractum of Chinese herbs, possessing the dual characteristics of absorbency and an anti-microbial, were investigated in weaned pigs.

In comparison to other studies evaluating activated charcoal, CHC demonstrated performance and health benefits at a lower dose. We used a dose from $500 \mathrm{mg} \mathrm{kg}{ }^{-1}$ to $2000 \mathrm{mg} \mathrm{kg}{ }^{-1}$, equivalent to $0.05 \%$ to $0.2 \%$, and reported significantly greater growth performance and lower diarrhea incidence at a dose of $500 \mathrm{mg} \mathrm{kg}{ }^{-1}(0.05 \%)$. This effective dose was lower than that reported in other studies: $0.25 \%$ activated charcoal in African catfish juveniles, $0.3 \%$ bamboo charcoal in fattening pigs, ${ }^{28}$ $0.5 \%$ bamboo charcoal in chicken, ${ }^{29} 0.7 \%$ in Nile tilapia, ${ }^{30}$ and $1 \%$ bamboo charcoal in ducks. We believe that the use of different parameters during processing, such as temperature and activation reagents, can result in different characteristics of the activated charcoal in terms of surface area, pore size and absorption potential. In the above-mentioned studies, the specific characteristics of the activated charcoal product used were not reported, thus comparison of the absorption capacity with our wood charcoal to explain differences in effective concentrations could not be made. Thus, the lower effective dose reported in the current study may be due to the combination of activated charcoal and extractum from Chinese herbs.

Activated charcoal has also been used for the absorption of toxins in a variety of feed materials. Some studies reported that activated charcoal showed a limited effect on toxin absorption. ${ }^{31}$ In vitro assays in our laboratory showed that the absorption rate of CHC on the mycotoxins DON, ZEN, AFB1 and OTA was above $90 \%$. Once absorbed, the complex of $\mathrm{CHC}$ and toxins was stable in a physiological solution, and was not readily separated through desorption tests (unpublished data).

In this study, CHC improved serum IgM, IgG and IL-1 $\beta$ levels and increased the concentration of SIgA in the duodenum and

Table 5 Effects of graded levels of $\mathrm{CHC}$ on the intestinal microflora in weaned piglets ${ }^{a}(n=6)$

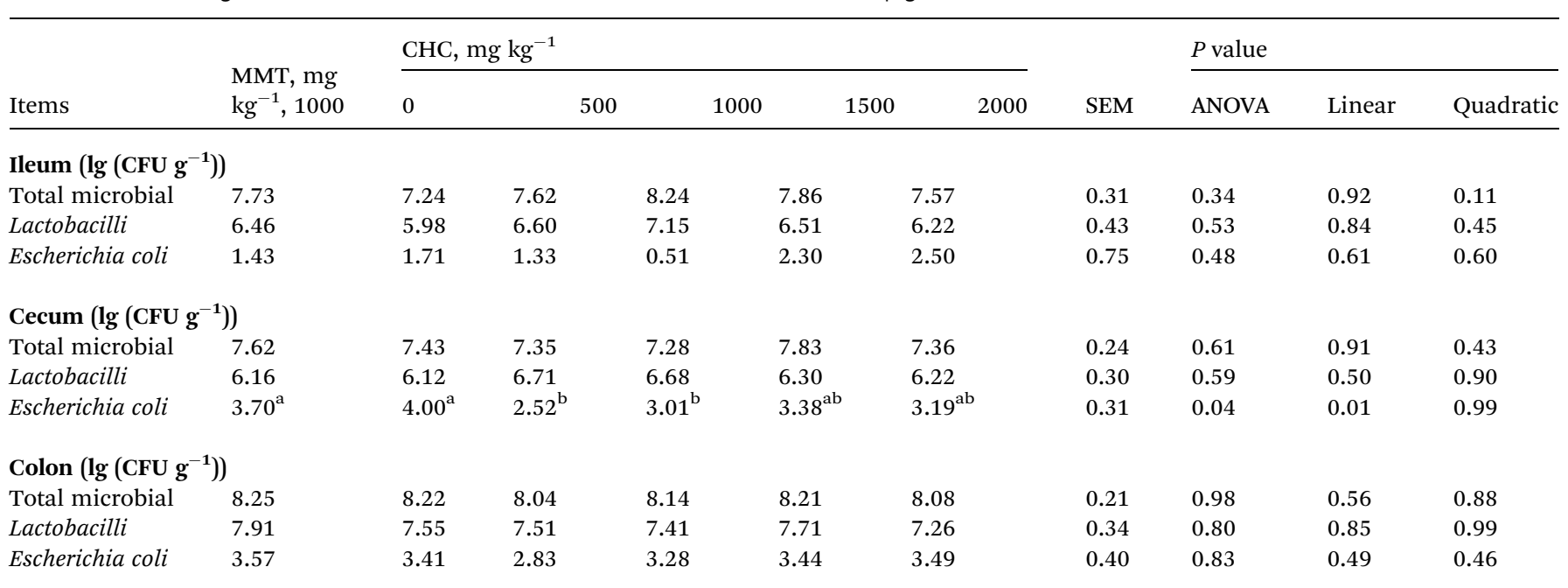

\footnotetext{
${ }^{a} \mathrm{a}, \mathrm{b}, \mathrm{c}$ Means within the same row without common superscripts differ significantly $(P<0.05)$.
} 
Table 6 Effects of graded levels of $\mathrm{CHC}$ on serum hormones in weaned piglets ${ }^{a}(n=6)$

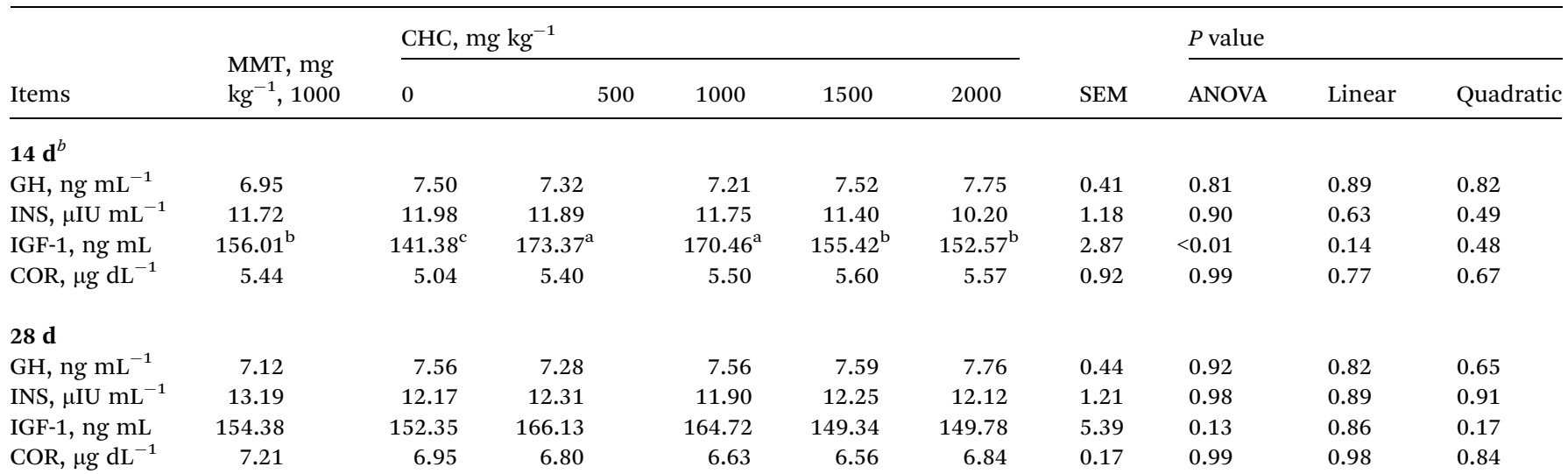

${ }^{a}$ a,b,c Means within the same row without common superscripts differ significantly $(P<0.05) .{ }^{b}$ GH growth hormone, INS insulin, IGF-1 insulin-like growth factor-I, COR cortisol.

jejunum, which demonstrated that $\mathrm{CHC}$ was beneficial in terms of the body's immune responses. IgM is the first immunoglobulin in the host to respond when foreign antigen is encountered and plays a key role in the defense against infection, along with the main immunoglobulin IgG. The IL-1 family of cytokines are major mediators of innate immune reactions. IL-1 $\beta$, sharing $24 \%$ identical amino acids with IL- $1 \alpha,{ }^{32}$ is secreted by an unconventional protein secretion pathway and acts in a paracrine manner or systemically. ${ }^{33}$ The major source of IL-1 $\beta$ is the sentinel cells of the innate immune system (macrophages and monocytes). ${ }^{34}$ Other types of cells like epithelial cells, endothelial cells and fibroblasts ${ }^{35}$ can also produce IL-1 $\beta$. The main function of IL- $1 \beta$ is to control proinflammatory reactions in response to tissue injury by bacteria or viruses. ${ }^{36,37} \mathrm{CHC}$ also improved IgM, IgG and IL-1 $\beta$ levels in sera, further confirming the effect of $\mathrm{CHC}$ on activation of innate immunity.

CHC comprised extracts from four types of Chinese herbs that contained numerous active compounds such as $\alpha$-phellandrene, camphene, $\alpha$-cedrene, borneol acetate, elemol, isoborneol, carvone, trans-carveol, $\alpha$-terpineol and triterpene saponins. ${ }^{17-20}$ These active compounds exert anti-inflammatory and anti-oxidant activity. The decreased concentration of MDA in the duodenum and jejunum indicated that $\mathrm{CHC}$ enhanced the body's scavenging effect on various reactive oxygen species, thereby effectively inhibited the production of the lipid peroxide product MDA. In the examination on the adverse effects of $\mathrm{CHC}$, we assayed hematological indices. The results showed no significant differences among all treatments in the doses of 500 and $1000 \mathrm{mg} \mathrm{kg}^{-1}$ of CHC. Even higher dose $\left(5000 \mathrm{mg} \mathrm{kg}^{-1}\right)$ did not show significant differences. We also assayed antioxidant indices of liver and kidney while CHC significantly decreased liver MDA but didn't significantly change in kidney (data not shown).

IGF-1 is an important mediator of tissue growth and differentiation, especially during the postnatal period. ${ }^{38}$ The liver is the major site of synthesis of IGF-1, but it is also synthesized in other tissues including the gastrointestinal tract. ${ }^{39}$ In pigs, pharmacological doses of IGF-1, given orally to colostrum- deprived 5-d-old piglets, increase electrolyte and nutrient absorption. ${ }^{40}$ Neonatal pigs fed formula supplemented with IGF-1 from birth to $4 \mathrm{~d}$ of age showed increased mucosal growth. The IGF-1 concentration increases steadily as animals grow, unlike growth hormone that shows large circadian variations. ${ }^{41}$ Many studies have reported that plant extracts improve the secretion of IGF-1. ${ }^{42}$ In this study, CHC containing four types of Chinese herbs also increased sera IGF-1 levels.

The combined functions of both activated charcoal and the extractum of Chinese herbs improved intestinal morphology, as demonstrated by villus height and the ratio of villus height to crypt depth in the duodenum and jejunum. Gastrointestinal development is modulated by numerous factors. On the one hand, insulin-like growth factors are considered to be essential among these factors. IGF1 can act on the intestinal epithelium via the endocrine effects of circulating IGF1 derived primarily from hepatocytes, and the paracrine effects of locally-expressed IGF1 synthesized by the intestinal mesenchyme. ${ }^{43}$ The increased IGF-1 levels were positively correlated with growth performance and gastrointestinal growth, which is consistent with the literature. ${ }^{44}$ On the other hand, a decreased concentration of intestinal MDA and increased levels of duodenum and jejunum SIgA indicated that CHC reduced the severity of intestinal damage. ${ }^{45}$ SIgA predominantly acts at the mucosal surface, where it binds antigens and prevents viral and bacterial invasion of epithelial surfaces. The role of SIgA in local immunity is manifold. ${ }^{46}$ It can prevent bacteria and viruses from adsorbing on the surface of mucosal epithelial cells and forming colonies. It also exerts strong agglutination properties, which can lead to the agglutination of bacteria to form larger particles that can be easily removed. ${ }^{47} \mathrm{It}$ is for these reasons that $\mathrm{CHC}$ can improve duodenum and jejunum morphology. This is consistent with the reported effect of complex bamboo charcoal with wood vinegar.

Clay as MMT has been reported to increase the numbers of beneficial bacteria such as Bifidobacteria and Lactobacillus and decrease the proportion of harmful bacteria such as Clostridium and $E$. coli in the small intestine ${ }^{23,24}$ in weaned pigs. In our study, CHC decreased the numbers of $E$. coli in the cecum at 
a dose of $500 \mathrm{mg} \mathrm{kg}{ }^{-1}$. Higher doses of CHC showed no significant change in the numbers of beneficial Lactobacillus and harmful E. coli. These findings may be due to the relatively well-controlled composition of the feed and environment during this study resulting in limited exposure to challenge for weaning piglets.

Possible reasons for the observed positive effect of $\mathrm{CHC}$ on growth performance are listed below. Firstly, CHC reduced the speed with which feed passed along the digestive tract, prolonging the digestion time and allowing the feed to be fully digested and absorbed. Secondly, CHC improved the gut microbial composition, reducing harmful bacteria such as $E$. coli and adsorbing toxins, which had beneficial effects on intestinal morphology, which in turn, reduced the occurrence of diarrhea and improved nutrient digestibility. Thirdly, CHC enhanced cellular immunity and antioxidant capacity during the post-weaning period.

\section{Conclusions}

In this study, we report the numerous positive effects of the feed additive $\mathrm{CHC}$, a complex of active charcoal and extractum of Chinese herbs, in weaning piglets. CHC promoted growth performance, alleviated diarrhea, enhanced immune responses, improved intestinal morphology and positively affected the microflora. The optimal dose of CHC was determined to be 500 to $1000 \mathrm{mg} \mathrm{kg}^{-1}$ in this study.

\section{Conflicts of interest}

The authors declare no competing financial interests.

\section{References}

1 F. Smith, J. E. Clark, B. L. Overman, C. C. Tozel, J. H. Huang, J. E. F. Rivier, A. T. Blisklager and A. J. Moeser, Am. J. Physiol.: Gastrointest. Liver Physiol., 2010, 298, G352-G363.

2 J. C. Kim, C. F. Hansen, B. P. Mullan and J. R. Pluske, Anim. Feed Sci. Technol., 2012, 173, 3-16.

3 J. Stroka, Food Addit. Contam., 2011, 28, 259.

4 J.-P. Lallès, P. Bosi, H. Smidt and C. R. Stokes, Proc. Nutr. Soc., 2007, 66, 260-268.

5 H. Szajewska, P. Dziechciarz and J. Mrukowicz, Aliment. Pharmacol. Ther., 2006, 23, 217-227.

6 M. D. Subramaniam and I. H. Kim, J. Anim. Sci. Biotechnol., 2015, 6, 38.

7 P. A. Thacker, J. Anim. Sci. Biotechnol., 2013, 4, 35.

8 A. Anadón, J. Vet. Pharmacol. Ther., 2006, 29, 41-44.

9 R. Laxminarayan, A. Duse, C. Wattal, A. K. Zaidi, H. F. Wertheim, N. Sumpradit, E. Vlieghe, G. L. Hara, I. M. Gould, H. Goossens, C. Greko, A. D. So, M. Bigdeli, G. Tomson, W. Woodhouse, E. Ombaka, A. Q. Peralta, F. N. Qamar, F. Mir, S. Kariuki, Z. A. Bhutta, A. Coates, R. Bergstrom, G. D. Wright, E. D. Brown and O. Cars, Lancet Infect. Dis., 2013, 13, 1057-1098.

10 J. Gong, F. Yin, Y. Hou and Y. Yin, Can. J. Anim. Sci., 2014, 94, 223-241.
11 N. Hagemann, K. Spokas, H.-P. Schmidt, R. Kägi, M. Böhler and T. Bucheli, Water, 2018, 10, 182.

12 M. A. Abdel-Wahhab, A. A. El-Kady, A. M. Hassan, O. M. Abd El-Moneim and S. H. Abdel-Aziem, Food Chem. Toxicol., 2015, 83, 174-182.

13 M. Samanya and K. Yamauchi, J. Poult. Sci., 2001, 38, 289301.

14 J. Y. Choi, P. L. Shinde, I. K. Kwon, Y. H. Song and B. J. Chae, Asian-Australas. J. Anim. Sci., 2009, 22, 267-274.

15 C. B. Scott, C. A. Taylor and M. G. Bisson, J. Range Manage., 2001, 54, 274-278.

16 D. Yao, A. G. Vlessidis, Y. Gou, X. Zhou, Y. Zhou and N. P. Evmiridis, Anal. Bioanal. Chem., 2004, 379, 171-177.

17 T. Liu, L. Ye, X. Guan, X. Liang, C. Li, Q. Sun, Y. Liu, S. Chen, F. Bang and B. Liu, Int. J. Biol. Macromol., 2013, 54, 225-229.

18 M. Iranshahy, B. Javadi, M. Iranshahi, S. P. Jahanbakhsh, S. Mahyari, F. V. Hassani and G. Karimi, J. Ethnopharmacol., 2017, 205, 158-172.

19 N. Erkan, Food Chem., 2012, 133, 775-781.

20 G. Wenqiang, L. Shufen, Y. Ruixiang and H. Yanfeng, Nat. Prod. Res., 2006, 20, 992-998.

21 J. M. Heo, F. O. Opapeju, J. R. Pluske, J. C. Kim, D. J. Hampson and C. M. Nyachoti, J. Anim. Physiol. Anim. Nutr., 2013, 97, 207-237.

22 Q. W. Duan, J. T. Li, L. M. Gong, H. Wu and L. Y. Zhang, Asian-Australas. J. Anim. Sci., 2013, 26, 1614-1621.

23 M. S. Xia, C. H. Hu and Z. R. Xu, Anim. Feed Sci. Technol., 2005, 118, 307-317.

24 J. P. Wang, F. Chi and I. H. Kim, Anim. Feed Sci. Technol., 2012, 178, 158-166.

25 M. Song, Y. Liu, J. A. Soares, T. M. Che, O. Osuna, C. W. Maddox and J. E. Pettigrew, J. Anim. Sci., 2012, 90, 345.

26 M. Michael, M. Brittain, J. Nagai, R. Feld, D. Hedley, A. Oza, L. Siu and M. J. Moore, J. Clin. Oncol., 2004, 22, 4410-4417.

27 R. Janhan, M. A. Quaiyum, N. Janhan, T. Akhter and M. S. Islam, Int. J. Fish. Aquacult., 2014, 6, 87-93.

28 G. M. Chu, C. K. Jung, H. Y. Kim, J. H. Ha, J. H. Kim, M. S. Jung, S. J. Lee, Y. Song, R. I. H. Ibrahim, J. H. Cho, S. S. Lee and Y. M. Song, J. Anim. Sci., 2013, 84, 113-120.

29 S.-H. Kim, I.-C. Lee, S.-S. Kang, C.-J. Moon, S.-H. Kim, D.-H. Shin, H.-C. Kim, J.-C. Yoo and J.-C. Kim, J. Life Sci., 2011, 21, 805-810.

30 M. Abdel-Tawwab, G. O. El-Sayed and S. H. Shady, Aquaculture, 2017, 479, 17-24.

31 A. Piva, G. Casadei, G. Pagliuca, E. Cabassi, F. Galvano, M. Solfrizzo, R. T. Riley and D. E. Diaz, J. Anim. Sci., 2005, 83, 1939-1947.

32 E. Dunn, J. E. Sims, M. J. H. Nicklin and L. A. J. O'Neill, Trends Immunol., 2001, 22, 533-536.

33 M. Keller, A. Rüegg, S. Werner and H.-D. Beer, Cell, 2008, 132, 818-831.

34 E. V. Granowitz, B. D. Clark, E. Vannier, M. V. Callahan and C. A. Dinarello, Blood, 1992, 79, 2356-2363.

35 E. Hoffmann, A. Thiefes, D. Buhrow, O. Dittrich-Breiholz, H. Schneider, K. Resch and M. Kracht, J. Biol. Chem., 2005, 280, 9706-9718. 
36 M. Gaestel, A. Kotlyarov and M. Kracht, Nat. Rev. Drug Discovery, 2009, 8, 480-499.

37 C. A. Dinarello, Annu. Rev. Immunol., 2009, 27, 519-550.

38 H. M. Hammon and J. W. Blum, Domest. Anim. Endocrinol., 2002, 22, 155-168.

39 J. I. Jones and D. R. Clemmons, Endocr. Rev., 1995, 16, 3-34.

40 A. N. Alexander and H. V. Carey, Am. J. Physiol.: Gastrointest. Liver Physiol., 1999, 277, G619-G625.

41 L. Van Landeghem, M. A. Santoro, A. T. Mah, A. E. Krebs, J. J. Dehmer, K. K. McNaughton, M. A. Helmrath, S. T. Magness and P. K. Lund, FASEB J., 2015, 29, 2828-2842.
42 L. Fan, M. Dou, X. Wang, Q. Han, B. Zhao, J. Hu, G. Yang, X. E. Shi and X. Li, J. Anim. Sci., 2018, 96, 5144-5151.

43 S. F. Bortvedt and P. K. Lund, Curr. Opin. Gastroenterol., 2012, 28, 89-98.

44 N. D. Cameron, E. McCullough, K. Troup and J. C. Penman, J. Anim. Breed. Genet., 2003, 120, 228-236.

45 J. Wan, F. Jiang, Q. Xu, D. Chen and J. He, RSC Adv., 2016, 6, 87026-87035.

46 P. Brandtzaeg and F.-E. Johansen, Immunol. Rev., 2005, 206, 32-63.

47 A. Cerutti, Nat. Rev. Immunol., 2008, 8, 421-434. 